\title{
Temettuat Defterlerine Göre Karadere Divanı
}

Turgut Subaşı ${ }^{1}$

Melih Barçın²

\section{Özet}

Sınırlarının değişmesiyle birlikte Osmanlı Devleti'nin vergi toplama şeklinde ve oranlarında da değişiklik olmuştur. Özellikle, bozulan merkezi otorite ve yapılan savaşlarda alınan yenilgiler, hazinenin zayıflamasına neden olmuştu. Giriştiği ıslahat hareketlerinden istediği sonucu alamayan Osmanlı Devleti, kötü gidişi düzeltmek amacıyla zamanla bazı düzenlemeler yapmıştı. $\mathrm{Bu}$ düzenlemelerin en önemlilerinden biri de halktan alınacak vergilerdi. Toplanacak vergilerle hazineye girecek nakit para, devlet adamlarına iktisadi alanda planlı hareket etme fırsatı verecekti.

1844-1845 yıllarını kapsayan dönemde, devletin hâkim olduğu coğrafyada, halkın sahip olduğu arazi, emlâk, hayvan, eşya ve mal varlığının tespit edilerek vergilerin daha adil toplanması için "Temettuat Defteri" adında yeni bir kayıt çalışması başlatıldı. Temettuat Defterleri tutulduğu dönemin ekonomik ve sosyal durumunu gözler önüne sermesi bakımından özelikle tarih ve diğer bilim dallarına ışık tutmaktadır. Temettuat Defterlerinde, hanelerin bir senede elde ettiği gelir ve sahip olduğu mal varlı̆ı hane reisi adına kayıt altına alınarak vergilendiriliyordu. Bu sayede defterde adı geçen kişilerin sahip oldukları meslek, işledikleri toprak miktarı ve nev'i, elde edilen ürün miktarı ve hayvan sayıları merkeze kadar ulaştırımış oluyordu.

Çalışmamıza konu olan, günümüzde Sakarya ili, Adapazarı ilçesinin $20 \mathrm{~km}$ kuzeyinde bulunan Karadere Mahallesi'nin 1844 (Hicri 1260-1261) senesine ait Temettuat Defteri, Başbakanlık Osmanlı Arşivinde BOA, ML. VRD. TMT. 4183 sayısı ile kayıtlıdır. O dönemde Karadere Divanı 67 hanenin bulunduğu, kazanın diğer divanlarına göre oldukça büyük yerleşim birimi konumundaydı. Kandıra- Adapazarı yolu üzerinde olan Karadere Divanı, Kaymas kazasının en kalabalık Müslüman yerleşim birimiydi.

Anahtar Kelimeler: Sakarya ili, Kaymas, Temettuat Defteri, Karadere Divanı

${ }^{1}$ Yrd. Doç. Dr., Sakarya Üniversitesi, Fen Edebiyat Fakültesi, Tarih Bölümü, Sakarya, subasi@sakarya.edu.tr. (Makale gönderim tarihi: 03.03.2017, makale kabul tarihi: 13.03.2017)

${ }^{2}$ Yüksek Lisans Öğrencisi, Sakarya Üniversitesi, Sosyal Bilimler Enstitüsü, Tarih Anabilim Dalı, Yakınçağ Tarihi Bilim Dalı, Sakarya.

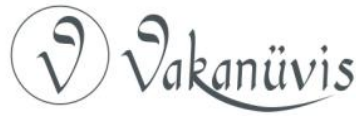




\section{Dividend Book of Karadere}

\section{Abstract}

The Ottoman State's tax collection methods and also rates changed with the change of boundaries. Especially deteriorating central authority and received successive defeats in the wars led to weakening of the public purse. The Ottoman State which did not obtain the desired result of reform movements made some arrangements in order to correct bad going over time. One of the most important of these arrangements was the taxes to be taken from the people. The cash money to be collected with taxes for treasure would give the opportunity to move in a planned manner to the statesmen in the economic area.

During the period from 1844 to 1845 , a new registration work called " Dividend Book " was initiated in order to collect tax more equitably by determining the existence of land, real estate, animals, goods and goods possessed by the people in the geography where the state is dominant. Dividend Books shed light especially on the history and other disciplines in point of showing up the economic and social situation of that period. In Dividend Books the income that dwellings had in a year and the property that they had, were recorded then taxed in the name of the householder. In this way, the profession of the people mentioned in the book, the amount and kind of land they work, the amount of product obtained and the number of animals were delivered to the center.

The Dividend book, the subject of our research, belongs the year of 1844 (A.H 1260-1261) of Karadere Quarter that located on $20 \mathrm{~km}$ north of today's Adapazarı district, Sakarya province, is registered in The Ottoman Archives of the Prime Minister's Office with the number BOA, ML. VRD. TMT, 4183. At that time, this settlement called the Karadere Divanı was pretty croweded dwelling unit with 67 households when compared to the other Divans of the district. Karadere Divan, which was on the way to Kandıra-Adapazarı, was the most crowded Muslim settlement of Kaymas borough.

Keywords: Sakarya province, Kaymas, Dividend Book, Karadere Divanı

\section{Giriş: Temettuat}

Literatüre; kazanç, kar elde etme, mal ve eşya sahibi olma olarak geçen Arapça kökenli "Temettu" kelimesinin çoğulu olan "Temettuat" Osmanlı Devleti için ise halkın mal ve mülk miktarı ile hayvan

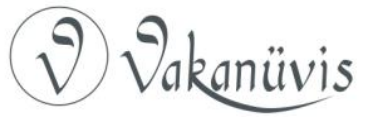


sayılarının kaydedildiği defterler olarak tanımlanabilir. ${ }^{3}$ Temettuat Vergisi ise Tanzimat döneminde yapılan değişiklikle önceden alınan vergilerin daha düzenli toplanması için diğer vergilerin kaldırılarak köylü, şehirli, esnaf ve tüccar hane reislerinin bir yıllık kazançları üzerinden alınan vergidir. ${ }^{4}$

\section{Osmanlı'da Vergi Toplama biçimi ve Temettuat Defterleri}

XIX. Yüzyıl Osmanlı Devleti'nin idari, siyasi, kültürel ve sosyoekonomik değişim yaşadığı bir dönemdi. Avrupa'nın etkisiyle değişim yaşayan Osmanlı Devleti vergi toplama biçimini de elden geçirmişti. Geçen yüzyıllarda ağır vergiler ödeyen halkın daha da kötü duruma düşmesini engellemek amacıyla herkesin gelir, mal ve mülkünün tespit edilmesine karar verilmişti. Bu amaçla komisyonlar kurularak en doğru tespitlerin yapılması hedeflenmişti. Ayrıca değişik adlarla tahsil edilen vergilerin de tek kaleme indirilmesi yapılan hesaplamaların da doğru olmasını sağlayacaktı.

$\mathrm{Bu}$ amaca uygun olarak çalışmalar başlatıldı. Vergilerin herkesin kazancına uygun olarak toplanması için kanunlar hazırlandı. Böylece,

"iltizam sistemi kaldılmış, cizye, aşar gibi birkaç verginin dışında kalan bütün vergiler kaldırılarak, her kesin mutasarrıf olduğu emlak ve arazi-i mevcudesinin menafii ve temettuat-ı hasılasına ve kar ve ticaret ve iktidarına ve'l-hâsıl hal ve tahammüllerinin derecesine göre virgü namıyla bir vergi alınması kararlaştırıldı. Ayrıca tayin olunacak verginin vaktinde ödenmesi ve bu konuda muhalefet edenlerin hapis ile cezalandırılması kararlaştırıldı." ${ }^{\prime 5}$

Temettuat Defterleri özellikle toplumun büyük bir kesimini oluşturan ve tarımla meşgul olan halk için önemli bir yere sahipti. Önceki dönemlerde kazançlarını devlete vergi olarak verdiklerinde kendileri kıt kanaat geçinirken yapılacak Temettuat çalışmalarıyla herkes gelirine göre vergi verecekti. XIX. yüzyılda Osmanlı Devleti'nin sosyal yapısını ve halkın ekonomik durumunu gözler önüne sermesi

${ }^{3}$ Ferid Devellioğlu, Osmanlıca- Türkçe Ansiklopedik Lügat, Ankara 1962, s.1288.

${ }^{4}$ M. Zeki Pakalın, "Temettü Vergisi", Osmanlı Tarih Deyimleri ve Terimleri Sözlüğü, c. III, İstanbul 1993, s.453.

${ }^{5}$ Nuri Adıyeke, "Temettuat Sayımları ve Bu Sayımları Düzenleyen Nizamname Örnekleri", OTAM, c. 11, s. 769.

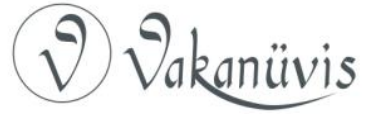


bakımından önemli bir yere sahip olan Temettuat Defterleri eyalet sistemine göre tertiplenmişti. Defterlerdeki bilgiler de alfabetik olarak bölümlere ayrılmıştı. ${ }^{6}$ Buna uygun olarak her eyalet alfabetik olarak kazalara ayrılmıştı. Temettuat Defterleri'nde yerleşim yerlerindeki haneler tek tek ele alınarak yaşayan hane reisinin adı altında emlak, arazi, küçük ve büyükbaş hayvanlar, koşum hayvanları ve tarla ve bahçelerinden elde edilen ürünler ve ağaç sayılarının tamamı hatta işletilen değirmen, kahvehane gibi mal varlığı olarak kayıt altına alınmıştı. Ayrıca birçok ailenin lakapları da bu belgelere nakledilmiştir.

\section{Kocaeli Mutasarrıflığı ve Kaymas Kazası}

İstanbul'un komşusu olan Kocaeli, Osmanlı Devleti'nin en önemli merkezlerinden biriydi. 1831 yılındaki nüfus sayımına göre izmit sancağı; İzmit, Adapazarı ve Sapanca, Akhisar, Geyve, İznik, Pazarköy, Yakakabad, Karamürsel, Kaymas, Şeyhler, Kandıra ve Gençli, Ağaçlı, Hendek ve Akyazı, Karasu, İpsafi, Sarıçayır, Beşdivan, Şile ve Taşköprü kazalarından oluşuyordu. ${ }^{7}$ Bu siyasi haritaya göre Kocaeli Batıda İstanbul'a, Doğuda Bolu'ya, Güneyde Bilecik'e ve Kuzeyde de Karadeniz'e kadar uzanıyordu. Temettuat Defterleri'nin tutulduğu 1844 senesine gelindiğinde Kocaeli Sancağı'nın kazaları; izmit, Adapazarı, Geybuze (Gebze), Kartal, Beykoz, Şile, Taşköprü, Beşdivan, Akabad (Akyazı), Ağaçlı, Kaymas, Kandıra, Şeyhler (Kaynarca), Karasu, Hendek, Abısafi, Sarıçayır, Dodurga, Taraklı, Geyve, Akhisar (Pamukova), Lefke (Osmaneli), Gölpazarı, İznik, Pazarköy, Yalakabad ve Karamürsel'den oluşmaktaydı. ${ }^{8}$ Günümüzde Sakarya, Yalova, Bursa, Bilecik illerine bağlı ilçeler ve İstanbul'un Anadolu yakasındaki bazı ilçeler Kocaeli'nin kazalarını oluşturuyordu. Osmanlı Devleti'nin kuruluşunda büyük hizmetleri olan Akçakoca'dan adını alan Kocaeli'nde Müslim ve gayr-i Müslim halk komşu köylerde yan yana barış içinde yaşamışlardı. Çalışmamıza konu olan Karadere Divanı da bağlı bulunduğu Kaymas kazasındaki tek Ermeni köyü olan Elmalı Zimmî köyüne komşu konumdaydı.

\footnotetext{
${ }^{6}$ Atilla Çetin, Kandıra, Kaymas-Akçaova (Akâbâd) Temettuat Defterleri, İzmit 2009, s.xiv.

${ }^{7}$ Kemal Karpat, Osmanlı Nüfusu (1830-1914), İstanbul 2003, s.150.

${ }^{8}$ Turgut Subaşı, "Sultan Abdülmecid döneminde Kocaeli", Uluslararası Gazi Akçakoca ve Kocaeli Tarihi Sempozyumu Bildirileri, Kocaeli 2015, s. 649.
}

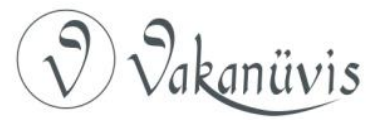


1844-1845 yıllarındaki Temettuat çalışmalarından anlaşıldığına göre adı "Kaymas"9 olarak bilinen bu kazanın merkezi büyük olmasa bile, kapladığı coğrafya ve bağlı bulanan köyler ve divanlar ${ }^{10}$ ile Kandıra'dan daha geniş alana yayılmış bir yerleşim birimiydi. Sınırının Kuzey ucu Oflak Tepesine dayanırken, güneyde ise Serdivan-ı Zimmî Divanı'na (Serdivan) kadar uzanıyordu. Kaymas Kazası'nda, Osmanlı Devleti'nin ilk nüfus sayımı olan 1831'deki kayıtlarda Müslüman kişi sayısı 3388 iken reaya olarak kaydedilenlerin sayısı ise 814 kişiydi. ${ }^{11}$ Kaymas'ın yönetim merkezi günümüzde Sakarya iline bağlı bir mahalle olan Salmanlı'ydı. ${ }^{12}$ Türkiye'nin kuruluşundan sonra yeniden oluşturulan idari birimlerde Kaymas kaza statüsünü kaybetmişti. 1954'te Sakarya ili oluşturulunca eskiden Kaymas'a bağı olan bazı divanlar Kocaeli'ne bağlı kalırken bazıları da Sakarya iline bağlanmıştı. Günümüzde divan yapılanması olmadığından eski adı divan veya karye olan bu yerleşim yerleri varlıklarını mahalle olarak devam ettirmektedirler. Kaymas, kaza statüsünü kaybettikten sonra "Araman" divanına Kaymas adı verilmiştir. Bugün Kaymas, Kandıra'ya bağlı bir mahalle konumundadır.

Yukarıda bahsedildiği gibi yüz yetmiş yıl öncesinde büyük bir kaza olan Kaymas'ın Temettuat Defterlerine göre (31 defterde) 33 divanı ve bu divanlara bağlı 114 köyü bulunuyordu. Kaymas Kazasına bağlı bu divanlar; Dökdüren Divanı, Çubuklu Divanı, Serdivan-ı Zimmî Divanı (Rum), Badın Divanı, Hıcılı Divanı, Karadere Divanı, Calatcak Divanı, Hızırlar Divanı, Erikli Divanı, Nefs-i Kaymas Divanı, Incecik Divanı, Pelidpınar Divanı, Sinanlı ve Bilallı Divanı, Sarıgazi Divanı, Anbarcı Divanı, Terziler Divanı, Akçakise Divanı, Araman Divanı, Hatablı-i Kebir Divanı, Elmacık Divanı, Alefli Divanı, Sarıca Ali Divanı, Hatablı-i Sağir Divanı, Arabacılar Divanı, Çerkeşli Divanı, Ahmet Hacılar Divanı,

\footnotetext{
${ }^{9}$ Atilla Çetin, age, s.xiv.

${ }^{10}$ Karadeniz Bölgesi'nde Sinop-Kocaeli illeri arasında bulunduğu iddia edilen “divan"lar, tarihçiler tarafından köy (karye) ile nahiye arasında kalan ve artık hükmü kalmayan bir idari birim olarak kabul edilmektedir. Bkz. Cevdet Yılmaz, "Türkiye'de Tarihçiler ve Coğrafyacılar Tarafından Farklı Anlamlarda Kullanılan Bir Terim: Divan", History Studies, Volume 2/1, 2010, s. 274.

${ }^{11}$ Mehmet Kaya, "XIX. Yüzyılda İzmit (Kocaeli) Sancağı'nın Demografik Durumu ve İskân Siyaseti", Ankara Üniversitesi, Dil ve Tarih-Coğrafya Fakültesi, Tarih Bölümü, Tarih Araştırmaları Dergisi 01/2007, s.65.

${ }^{12}$ Salmanlı'nın adı Temettuat defterlerinde "Selmanlı" olarak geçmektedir.
}

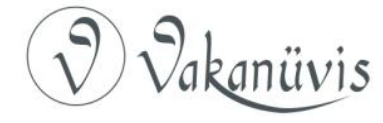


Hasbeyli Divanı, Mülküşehsuvar Divanı, Hacılı Divanı, Hacılı Divanı, Seyyid Aliler Divanı, Oruçkan Divanı ve İmamlar Divanı'dır. Bu divanlardan Elmalı Zimmî Köyü ve Serdivan-ı Zimmî Divanı ayrı ayrı kaydedilmiştir. Diğer divanlar yakın köylerin birleştirilmesiyle oluştuğundan bağlı köyler olarak kaydedilmiştir. Bunların içinde Karadere Divanı, hane sayısının çok olması nedeniyle komşusu olan Elmalı Zimmî köyü gibi ayrı olarak yönetilip deftere de o şekilde kaydedilmiştir. ${ }^{13}$

\section{Karadere Divanı}

Günümüzde Sakarya ili merkez Adapazarı ilçesine bağlı bir mahalle olan Karadere ile ilgili literatüre geçen çalışma yeterli değildir. Bu az sayıdaki çalışmalar arasında en önemlisi Prof. Dr. Atilla Çetin'in büyük bir azimle hazırladığı ve başvuru eseri olarak niteleyebileceğimiz "Kandıra, Kaymas-Akçaova (Akâbâd) Temettuat Defterleri (18441845)" adlı kitabıdır.

Günümüzün siyasi haritası ile XIX. Yüzyılın idari sınırları, yaşanan değişikliklerden en çok etkilenen yerlerden olan Kocaeli Vilayeti, 1954 yılında Doğu bölümünün Sakarya adı ile ayrılmasından sonra daha dar alana sahip olmuştur. Yeni kurulan Sakarya ilinin merkez ilçesi konumundaki Adapazarı ilçesi de Kocaeli Sancağının en önemli kazalarından biri konumundadır. Karadere Divanı, Temettuat Defterleri'nde “Bolu Eyâleti hâvi olduğu kazalardan Kocaeli Sancağı'na tâbi Kaymas Kazası'nda kâin Karadere Karyesinde mukîm ahalinin emlâk ve arazi ve temettuatının mikdarı" şeklinde geçmektedir. ${ }^{14}$

\section{Nüfus Yapısı}

Karadere Divanı, Temettuat Defterine kayıtlı 67 haneden oluşmaktaydı. Genellikle geniş aile yapısına sahip olan Osmanlı toplumunda, bir hanede tam olarak kaç kişinin yaşadığını gösteren kayıt bulunmamaktadır. ${ }^{15}$ Temettuat Defterlerinde de sadece hane reisinin adı geçtiğinden tam sayıya ulaşmak mümkün olmadığından bu çalışmada Ömer Lütfi Barkan tarafından araştırmacılara yol gösteren

\footnotetext{
${ }^{13}$ BOA, ML. VRD. TMT.4183, BOA, ML. VRD. TMT,4179.

${ }^{14}$ Bkz. BOA, ML. VRD. TMT.4183.

${ }^{15}$ Halil İnalcık \& Donalt Quataert, Osmanlı Imparatorluğu'nun Ekonomik ve Sosyal Tarihi, İstanbul 2004 C.2, s. 908.
}

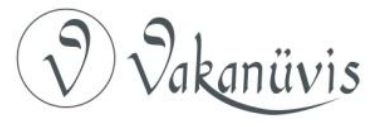


"Tarihi Demografi Araştırmaları ve Osmanlı Tarihi" adlı makalesindeki ${ }^{16}$ anlayışa göre her hanenin 5 kişiden oluştuğu gerçeğini kabul ederek hareket edilmiştir. Buna göre Karadere Divanı'nın nüfusu aşağıdaki gibidir.

Tablo:1 Karadere Karyesinde Nüfus- 1844

\begin{tabular}{|c|c|c|}
\hline KÖY & HANE SAYISI & NÜFUS (HANE X 5) \\
\hline KARADERE DIVANI & 67 & 335 \\
\hline
\end{tabular}

Kaynak: BOA, ML. VRD. TMT.4183

Bu durumda Karadere Karyesi 1844 yılında Kaymas Kazasının Serdivan-ı Zimmî Divanı'ndan sonra en büyük yerleşim alanı konumundadır. Osmanlı Devleti'nde genel olarak Müslüman ve Gayr-ı müslim halkın ayrı ayrı ${ }^{17}$ yerleşimine örnek olan Karadere Divanında hane reislerinin mesleklerine göre köyde 1 imam, 1 hatib, 1 mısırcl, 1 menzilci, 1 sepetçi ve 65 tarım ve hayvancılık işiyle meşgul olan hane yaşamaktadır. ${ }^{18}$ Temettuat Defterlerinde adı geçen kişiler vergi veren hane reisleridir. Bunların isimleri, tahrir defterlerinde olduğu gibi " Ali veled-i Hüseyin" şeklinde yazılmayıp "veled" kelimesi yerine "Kalafatoğlu Mehmet bin ibrahim" örneğinde olduğu gibi "bin" kelimesi kullanılarak yazılmıştır. Bu şekilde lakap yazılarak hazırlanan temettuat defterleri aynı babanın çocuklarının tespiti hatta aynı soydan gelen diğer kişilerin tespitini kolaylaştırmıştır. Hane numaralarının kullanılmasıyla evlerin tam olarak yerleri de belirlenerek, daha sonra yapılacak olan çalışmalara rehber olması planlanmıştır.

${ }^{16}$ Ömer Lütfi Barkan, "Tarihi Demografi Araştırmaları ve Osmanlı Tarihi", Türkiyat Mecmuası, c. 10, İstanbul 1953, s. 1-26.

${ }^{17}$ Dilşah Cengiz, Adapazarı/Sögütlü Karyesi Temettuat Defteri Transkripsiyon ve Değerlendirilmesi, Yayımlanmamış Yüksek Lisans Tezi, Sakarya 2010, s. 34. ${ }^{18} \mathrm{M}$ ısırcı Hacı Abdullah, Menzilcinin Mustafa ve Sepetçi Kıbtiyan Şaban bin Ahmed ve Kıbti Hüseyin emlak ve arazi sahibi olmadıklarından hane sahibi olarak kaydedilmemişler fakat vergiye tabi tutulmuşlardır.

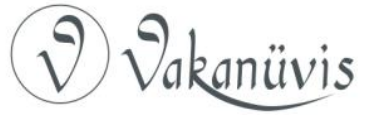


Depremler ve diğer doğal afetlerin yol açtığı yıkımların yanında, savaşlarla birlikte daralan devlet sınırlarının elden çıkan bölümündeki Müslüman ahalinin Anadolu'ya göçünden en çok etkilenen yerlerden biri de Kocaeli-Sakarya illerinin bulunduğu coğrafyadır. Özellikle Balkanlar ve Kafkaslarda kaybedilen topraklardan gelen göçmenler Buralarda iskân ettirilerek hem kullanılmayan topraklar kullanıma açılmış hem de gelenlere yeni yaşam alanları oluşturulmuştur. Fakat Kocaeli ve Sakarya bölgesinin en önemli sorunlarından olan toplum tipolojisindeki devamlılık sorunu Karadere Karyesinde kendini hissettirmemiştir. Çünkü Temettuat Defterlerindeki lakap ve hane reislerinin adlarına baktığımızda burada yaşayan ailelerin çoğunun hala yerlerinde yaşadığını görmekteyiz.

67 hane olarak kaydedilen Karadere Karyesinde ikamet eden kişilerin meslekleri de sahip oldukları mal varlıklarına bakıldığında ziraat ve hayvancılık olduğu görülmektedir. Aşağıdaki tabloda Karadere Karyesinde ikamet eden kişilerin \% 95,5'inin tarım ve hayvancılıkla geçimlerini sağladığı anlaşıımaktadır.

\begin{tabular}{|c|c|c|c|c|c|}
\hline KÖY & $\begin{array}{c}\text { Hane } \\
\text { Sayısı }\end{array}$ & Çiftçi & $\begin{array}{c}\text { Hane } \\
\text { Sayısına } \\
\text { Oranı (\%) }\end{array}$ & $\begin{array}{c}\text { Yıllık } \\
\text { Gelir } \\
\text { (Kuruş) }\end{array}$ & $\begin{array}{c}\text { Zuhurat } \\
\text { (Kuruş) }\end{array}$ \\
\hline $\begin{array}{c}\text { KARADERE } \\
\text { DiVANI }\end{array}$ & 67 & 65 & 97 & 47705 & 36450 \\
\hline
\end{tabular}

Tablo 2 - Karadere Divanı'nda tarımla uğraşan kesim-1844

Kaynak: BOA, ML. VRD. TMT.4183

Tarımın temel geçim kaynağı olduğu Karadere Divanı'nda köyün nüfusuna paralel olarak din görevlilerinin de iki kişi olduğu göze çarpmaktadır. Günümüzde devlet tarafından atanan imamlar o dönemde vakıflar tarafından finanse edilmekteydi. Halkın kurduğu vakıflar, din görevlilerinin geçimini sağlaması için gerekli çalışmaları yapıyordu. ${ }^{19}$ Fakat Karadere Divanındaki imam ve hatiplerin de üzerine kayıtlı Temettuat vardır. Geçim kaynaklarının kullanımı ve elde edilen

19 Fatih Odabaş, XIX. Yüzyılda Adapazarı'nın Sosyo-Ekonomik Yapısı, Yayımlanmamış Yüksek Lisans Tezi, İstanbul 2007, s. 21.

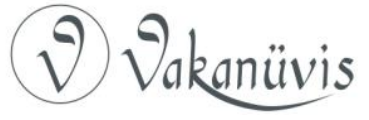


gelirlere bakıldığında, Karadere Divanı'nda geçim standardının Osmanlı Devleti'nin diğer bölgelerine göre yüksek olduğu söylenebilir. ${ }^{20}$

\section{Ziraat}

Temettuat Defterleri kayıtlarına göre 1844 senesinde Karadere Divanı'nda işlenebilen ve ekonomik getirisi olan tarla, çayır, bahçe ve ağaçlık gibi arazilerin toplamı 709,5 dönümdür. Bu arazilerin 679 dönümü tarla, 27,5 dönümü çayır ve 3 dönümü dut ağacıdır. Bu arazilerin dışında yine hane sahiplerine ait olan fakat tarım dışı olarak kullanılan arazi miktarı ise 1119 dönüm olarak kaydedilmiştir. Bu araziler tarım için kullanılmasa dahi hayvanlarının otlaması için kullanılan oldukça geniş bir alan olduğu göze çarpmaktadır. Karadere Divanda hane başına 10,59 dönüm işlenebilen tarla düşmektedir. Bu duruma göre dönemin ortalaması 22 dönümdür ve bu rakama göre ortalamanın yarısı düzeyindedir. ${ }^{21}$

Divan kayıtlarında 4, 7, 14, 19, 21, 25, 34, 47 ve 48 numaralı hanelerde ikamet eden Karkaroğlu, Eseoğlu, Kartazoğlu, Abdullah Paşaoğlu, Tunusluoğlu, Kelhasanoğlu, Taviloğlu, Fazlıŏlu ve vergi vermeyen Divan İmamı Mehmed Efendi, divanda tarla ve hayvan varlığı bakımından ön plana çıkmaktadırlar. Bu ailelere ait işlenebilen tarla ortalaması 23,3 dönümdür.

Karadere Divanı'nda üretilen tarım ürünleri, 1844-1845 tarihli Temettuat Defterleri'nin genelinde olduğu gibi hınta (buğday), şa'ir (arpa), alaf (yem için ot, saman), kapluca (küçük taneli buğday) ve tohum (keten) bitkilerdir. Aşağıdaki tablo Karadere Divanı'nda ekimi yapılan bitkilerin toplam miktarlarını göstermektedir.

${ }^{20}$ Turgut Subaşı ve Mahmut Araz, "Temettuat defteri Kayıtlarına Göre Söğütlü Karyesi”, Sakarya Üniversitesi Fen Edebiyat Dergisi, C. 15, S. 1, Sakarya 2013, s. 8.

${ }^{21}$ Gülfettin Çelik, XVI-XIX. Yüzyıllarda Gebze (Sosyo-Ekonomik Bir inceleme), Gebze 2003, s.123.

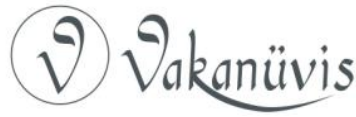


Tablo 3 - Karadere Divanı́nda tarla ve bahçe ürünleri üretimi 1844

\begin{tabular}{|c|c|c|c|c|c|c|}
\hline KÖY & Hınta & Şa'ir & Alef & Kaplıca & Tohum & Tohum \\
\hline $\begin{array}{c}\text { KARADERE } \\
\text { DiVANI }\end{array}$ & $\begin{array}{c}122 \\
\text { Kile }^{22}\end{array}$ & $\begin{array}{c}27,5 \\
\text { Kile }\end{array}$ & $\begin{array}{c}71 \\
\text { Kile }\end{array}$ & $\begin{array}{c}43,5 \\
\text { Kile }\end{array}$ & $\begin{array}{c}26,5 \\
\text { Kile }\end{array}$ & $\begin{array}{c}21,5 \\
\text { Şinik }\end{array}$ \\
\hline
\end{tabular}

Kaynak: Boa, ML. VRD. TMT.4183

Yapılan zirai çalışmalara bakıldığında dönemin tarla ve hane oranlarına göre her hanenin kendi ihtiyacı olan ürünü ektiği görülmektedir. Ekim işleri hane halkının yaşamını sürdürmesi için ekmeklik buğday ve hayvanlarının bakımı için gerekli olan yemlik ürünler olarak göze çarpmaktadır. Özellikle "hınta" ekiminin çok olması, ihtiyaç fazlası ürünlerinin ticaretini yaptıklarını ya da takas yöntemi ile ihtiyaçlarını karşıladıklarını göstermektedir.

\section{Hayvancılık}

Tarım alet ve makinelerinin henüz tam olarak kullanılmaya başlanmadığı XIX. Yüzyıl Osmanlı toplumunda, iş gücü açığını kapamak için doğal olarak hayvan gücü kullanılmıştır. Hayvanlar hem tarlaların sürülüp ekime hazır hale getirilmesinde, hem de ürünlerin hasadından sonra gerçekleştirilen harmanın kaldırılmasında kullanılmaktadır. Ayrıca tarlaların gübre ihtiyacı yine hayvanlar tarafından karşılanmaktadır. Bununla birlikte her ev için gerekli olan et, süt, tereyağı, deri gibi ürünler için hayvan bakımı önemliydi. ${ }^{23}$ Taşrada ikamet eden Osmanlı toplumu için tarım ve hayvancılığın içi içe olduğu bu dönemde hayvanların bakımı ve beslenmesi oldukça önemliydi. Hayvanların hastalanması intimali ve işleri zamanında yetiştirebilmek amacıyla her hanede en az bir çift Camus öküzü veya karasığır öküzü olduğu kayıtıdır.

${ }^{22}$ Eskiden Anadolu'da tahıl ölçümünde kile biriminden yararlanılırdı. İstanbul kilesi yaklaşık $25 \mathrm{~kg}$, başka yerlerde kullanılan kile ise yaklaşık 18 kg gelirdi. Kilenin dörtte birine Şinik denirdi. Bkz. Mustafa Şenel, "Türkiye Türkçesi Ağızlarında Ölçü Birimleri”, Karadeniz (Black Sea-Черное Mope) Yıl 3 Sayı 12, s.83.

${ }^{23}$ Tevfik Güran, XIX. Yüzyılda Osmanlı Tarımı, İstanbul 1998, s. 100.

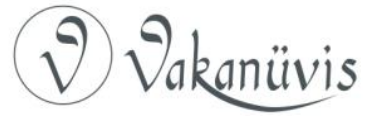


1844 yılı Temettuat Defteri kayıtlarına göre Karadere Divanı'nda toplam 265 hayvan vardır. Bu hayvanların 245 adedi büyükbaş ve 20 adedi küçükbaş hayvandan oluşmaktadır. Sanayi devriminin etkilerinin henüz etkisini göstermediği Osmanlı Devleti'nde köylerde yaşayan toplumun en az kendisi kadar önem verdiği büyükbaş hayvanların sayıca fazlalığı burada da kendini göstermektedir. Binlerce yıl boyunca tarımın temel taşı olan saban ve öküz ikilisi makineli tarımın olmadığı bu dönemde de Karadere Divanı'nın en önemli parçası durumundadır. Her alanda Avrupa'nın gerisinde kalan Osmanlı Devleti tarım konusunda da kendini henüz yenileyememiştir. ${ }^{24}$ Karadere Divanı'nda hayvan cins ve sayıları aşağıdaki tabloda gösterilmiştir.

Tablo 4 - Karadere Divanı'nda büyükbaş ve küçükbaş hayvanların cinslere göre dağılımı-1844

\begin{tabular}{|c|c|c|c|c|c|c|c|c|c|c|}
\hline : & 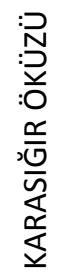 & 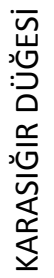 & 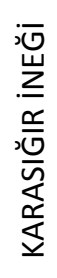 & 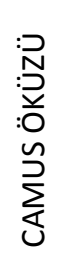 & 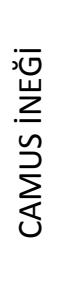 & $\sum_{\substack{\infty \\
\ll}}$ & 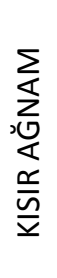 & 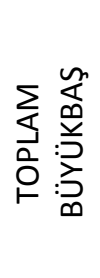 & 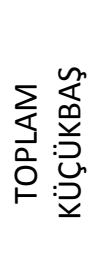 & 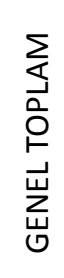 \\
\hline $\begin{array}{c}\text { KARADERE } \\
\text { DiVANI }\end{array}$ & 162 & 3 & 34 & 20 & 26 & 15 & 5 & 245 & 20 & 265 \\
\hline
\end{tabular}

Kaynak: Boa, ML. VRD. TMT.4183

Tarıma dayalı bir yaşam biçimini benimseyen Karadere Divanı sakinleri için tarla işçiliği en önemli meşguliyet olduğundan her hanede en az bir çift karasığır öküzü ya da bir çift camus öküzü göze çarpmaktadır. 1844 yılı Temettuat Defteri kayıtlarında tarlaların ekime hazır hale gelmesi için 162 baş ağır sürüm hayvanı beslenmektedir. Buna göre divanda hane başına 2,5 baş öküz düşmektedir. Bu da her hanenin tarıma verdiği önemi göstermektedir.

Karadere Divanı Temettuat Defterlerine göre sahip olunan hayvanların değeri ile ilgili bir kayıt yoktur. Fakat her hayvanın sütü, eti ya da derisinden elde edilen yıllık ortalama gelir kayıt altına alınmıştır.

${ }^{24}$ Halil İnalcık, Osmanlı Imparatorluğu Toplum ve Ekonomi, İstanbul 1996, s. 2.

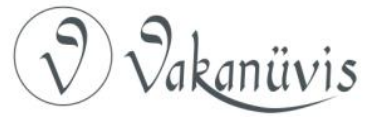


Bu durum ortalama olarak alınmıştır. Bir sağılır camusun yıllık 30 kuruş, bir sağılır karasığır ineğin de yıllık 15 kuruş sahibine para kazandırdığı öngörülmüştür.

Kocaeli Yarımadası'nın en doğu ucunda ${ }^{25}$ kurulu bulunan Karadere Divanı, Adapazarı Ovası'nın çark deresi tarafından, ayrıca küçük küçük derelerle sulanan bölgesindedir. Dolayısıyla ova tarımı yapıldığından elde edilen ürünler dönüm bazında bereketi de beraberinde getirmiştir. Engebeli arazi az olduğundan bakmaya gerek görmedikleri küçükbaş hayvan sayısı 20 adet ile sınırlı kalmıştır ve bunlarında 5 tanesi kısır niteliktedir.

\section{Vergiler}

Devletleri ayakta tutan temel gelir kaynağı olan vergiler, kuruluşundan itibaren Osmanlı Devleti'nin de en önemli kalemi olmuştur. İslam dininin etkisiyle şer'i ve örf'i vergi ${ }^{26}$ olarak tahsil edilen bu ücretler Müslim ve gayr-i Müslim halktan zekât, cizye, öşür ve haraç adı altında alınmıştır. Özellikle şer'i vergi olarak adlandırılan vergiler Osmanlı Devleti'nin temel vergi dilimini oluşturmuştur. Zekât Müslüman ahalinin malının 1/40'ı oranında verdiği vergidir. Bu vergiye tabi olan tebaanın belirli miktarda hayvan ve arazi gibi varlığa sahip olması gerekiyordu. Öşür vergisi ise yine Müslüman ahalinin tarla, bağ ve bahçelerinde yetiştirdiği ürün üzerinden ödediği $1 / 10$ oranındaki vergidir. Şer'i vergi olarak toplanan fakat daha ziyade gayr-ı Müslim halkın ödediği vergi olan haraçta iki farklı kalem mevcuttu. Bunlardan biri olan harac-ı muvazzaf tarla işlemenin karşıllı̆ı olarak yılda bir kez toplanıyordu. harac-ı mFukasem ise tarlanın verimine göre belirli oranda tahsil ediliyordu. Cizye vergisi de aynı haraç gibi gayr-ı Müslim halktan toplanıyordu. Bu vergi Osmanlı Devleti'nin yönetiminde huzurlu bir yaşam sürmenin karşılığı olarak ödenmekteydi. ${ }^{27}$ Şer'i vergilerin toplanış amacına bakıldığında din farkının vergilerin sadece ismine etki ettiğini, inanç biçimlerinin farklı olmasının Müslüman olmayan ahaliye ödemekte zorlanacakları bir yük getirmediğini söyleyebiliriz.

\footnotetext{
25 Ümit Sergün, Kocaeli Yarımadası'nda Kırsal Yerleşme, İstanbul 1986. s.131.

${ }^{26}$ Yusuf Halaçoğlu , "Klasik Dönemde Osmanlı Devlet Teşkilatı”, Genel Türk Tarihi Ansiklopedisi, c. 6, Ankara 2002, s. 175.

${ }^{27}$ Halaçoğlu, agm. s. 176.
}

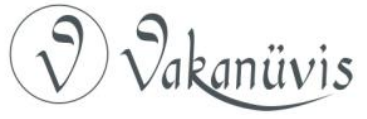


Padişahın iradesi doğrultusunda toplanan örf'i vergiler, din ile ilişkilendirilmeden geleneksel olarak tahsil edilmiştir. Bu vergiler, toplandığı bölgede gerekli olan harcamalar için ve ayrıca olağanüstü bir durumun meydana getirdiği olumsuzluğu düzeltmek amacıyla toplanıyordu. Aynî, nakdi ve hizmet karşılığı tahsil ediliyorlardı.

Karadere Divanı'nda vergi ödemeye mükellef olan hanelerin 1844 senesinde elde ettiği toplam kazanç 85200 kuruş olarak kaydedilmiştir. Bu paranın \% 56,7'lik bölümü (48705 kuruş) hane reisinin bir yıllık meslek kazancı iken, \% 43,3'lük bölümü (37200 kuruş) ise tarla ve bahçelerden elde edilen ürünlerdendir. Bu duruma bakıldığında Karadere Divanı'nın tarlalardan elde ettiği ürünlerin geçim kaynağı olarak önemli bir kısmını oluşturduğunu belirtebiliriz. Dolayısıyla iklim şartlarının bu karyede yaşayan halk üzerinde önemli bir yeri olduğu söylenebilir.

Tablo 5 - Karadere Divanı'nda Gelir-Vergi Oranı-1844

\begin{tabular}{|c|c|c|c|c|c|}
\hline \multirow{2}{*}{ KÖY } & \multirow{2}{*}{$\begin{array}{c}\text { HANE } \\
\text { SAYISI }\end{array}$} & $\begin{array}{c}\text { GELIR } \\
\text { Toplam } \\
\text { Yıllık } \\
\text { Gelir } \\
\text { (Kuruş) }\end{array}$ & $\begin{array}{c}\text { Toplam } \\
\text { Zuhurat } \\
\text { (Kuruş) }\end{array}$ & $\begin{array}{c}\text { Hane } \\
\text { Başıñen } \\
\text { Gelir } \\
\text { (Kuruş) }\end{array}$ & $\begin{array}{c}\text { Toplam } \\
\text { Vergi } \\
\text { (Kuruş) }\end{array}$ \\
\hline $\begin{array}{c}\text { KARADERE } \\
\text { DiVANI }\end{array}$ & 67 & 48705 & 37200 & 1282 & 11559 \\
\hline
\end{tabular}

Kaynak: Boa, ML. VRD. TMT.4183

Özellikle buğday ekiminin yoğun olduğu bölgede, arpa, alef ve kabluca ekimi de önemli bir yer tutar. Bu ürünlerin ekimine paralel olarak devlete ödenen öşür vergisi de senede 1210 kuruş ile buğday, 459,5 kuruş ile tohum olarak adlandırılan keten, 257 kuruş ile alef, 137,5 kuruş ile arpa ve 134,5 kuruş ile kabluca olarak kaydedilmiştir.

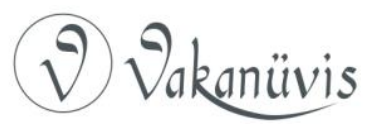




\section{Sonuç}

Avrupa ile ilişkilerin yoğunlaştığı Tanzimat döneminde Osmanlı Devleti, kendini yenileyebilmek ve yapılan ıslahatlara ve diğer yapılacak harcamalara finans sağlamak istemiştir. Bu doğrultuda yapılan çalışmalardan biri olan Temettuat Defterleri aynı zamanda kimin ne kadar mal ve mülk sahibi olduğunu ortaya çıkartmıştır. Bu defterler aynı zamanda devlet otoritesinin taşrada hissedilmesini sağlamıştır. Illk kez 1840 senesinde yapılan sayımları 1844-1845 senelerindeki kayıtlar izlemiştir.

Oflak Dağı'nın Adapazarı Ovası'yla birleştiği coğrafyada kurulu bulunan Karadere Divanı, Kandıra yolu üzerinde olması nedeniyle önemli bir yere sahiptir. Temettuat kayıtlarına göre Karadere Divanı, Bolu Eyâleti'ne bağlı Kocaeli Sancağı'nın Kaymas Kazası'nın köyü konumundadır. Incelenen dönemde Karadere 67 hanelik yapısıyla, Serdivan-ı Zimmî Divanı'ndan ${ }^{28}$ sonra Kaymas kazasının en büyük köyü konumundadır. Tarım ve hayvancılık faaliyetlerinin önemli olduğu Karadere divanında tarım ürünleri, bir evin yıllık ihtiyacını karşılayacak olan unun hazır edilmesi için buğday ve hayvanların yem ihtiyacını karşılamak için de arpa ve alef olarak öne çıkmaktadır. Üretmiş oldukları buğdayları başka yerlere giderek öğütmek yerine köyün içinden geçen derenin üzerine kurdukları değirmenleri kullanmışlardır. ${ }^{29}$ Burada bulunan değirmenler bölgedeki ticareti de canlandırması bakımından önemlidir. Keten ekiminin de yoğun olduğu köyde halk ham olarak ya da bez haline getirdikleri ketenleri arabalarıla Kandıra ve daha yakın olan Adapazarı'nda değerlendirmişlerdir.

Hane başına düşen gelir 1844 senesinde Karadere'de 1282 kuruş olarak gerçekleşmiştir. Bu durum ekonomik olarak iyi bir yerde olduklarını göstermektedir. Tam anlamıyla tarım ve hayvancılık yapılan köyde, dışarıdan ürün temin etmek yerine kendi ektiklerini kullanma yolunu benimsemişlerdir. Temettuat kayıtlarına göre bir senede 85905 kuruş gelir elde edilen köyde bu meblağın 11559 kuruşu devlet

\footnotetext{
${ }^{28}$ Serdivan-ı Zimmî Divanı 102 hanenin yaşadığı en büyük köydür. Bkz. BOA, ML. VRD. TMT. 4180.

29 "Asiyâb-ı Bab" olarak adlandırılan su değirmenleri, BOA, ML. VRD. TMT. 4183 numaralı defterde Karadere'de 4 hane üzerine kayıtlıdır.
}

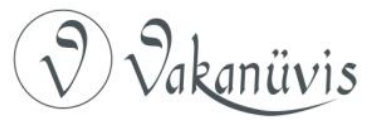


tarafından vergi olarak toplanmıştır. Kalabalık bir nüfusa sahip olan Karadere Divanı elde edilen ürünlerin vergisini belirlemiştir.

Hemen kuzeyinde Ermeni nüfusun yaşadığı Elmalı Köyü'nün olması ve Ermeni halkın zanaat sahibi, hizmetkâr ve gündelikçi olması iki köy arasında yakın ilişkilerin yaşandığına işaret etmektedir. ${ }^{30}$

1844-1845 Temettuat Defterlerine göre Karadere Divanı'nda yaşayan hane reisleri ve hane numaraları aşağıdaki gibidir.

\begin{tabular}{|c|c|c|}
\hline \multicolumn{3}{|c|}{ KARADERE DIVANI } \\
\hline $\begin{array}{c}\text { HANE } \\
\text { NO }\end{array}$ & HANE REISLERI & MESLEĞi \\
\hline 1 & İmam Hüseyin Efendi bin Ali & Ziraat \\
\hline 2 & Kalafatoğlu Mehmed bin İbrahim & Ziraat \\
\hline 3 & Ramazanoğlu Mehmed Ali bin Mehmed & Ziraat \\
\hline 4 & Karkaroğlu Ali bin Ahmed & Ziraat \\
\hline 5 & Karkaroğlu Mehmed bin Abdullah & Ziraat \\
\hline 6 & Kıtazoğlu Süleyman bin Ahmed & Ziraat \\
\hline 7 & Eseoğlu Mustafa bin Osman & Ziraat \\
\hline 8 & Fazlıoğlu Hüseyin bin İsmail & Ziraat \\
\hline 9 & Şabanoğlu Mehmed bin Osman & Ziraat \\
\hline 10 & Şabanoğlu Osman bin Mehmed & Ziraat \\
\hline 11 & Hasancıkoğlu Mehmed bin Hüseyin & Ziraat \\
\hline 12 & Durakoğlu Salih bin Ali & Ziraat \\
\hline 13 & Çataloğlu Mustafa bin Hasan & Ziraat \\
\hline 14 & Kaztazoğlu Osman bin Hüseyin & Ziraat \\
\hline 15 & Kadıoğlu Hüseyin bin Mehmed & Ziraat \\
\hline 16 & Kalafatoğlu Sarı Mehmed bin Ömer & Ziraat \\
\hline 17 & Kıcıoğlu Hasan bin İsmail & Ziraat \\
\hline 18 & Kıçıŏlu Ahmed bin İsmail & Ziraat \\
\hline 19 & Abdullahpaşaoğlu Mehmed Ali bin Hasan & Ziraat \\
\hline 20 & Kucuoğlu Ali bin Mustafa & Ziraat \\
\hline 21 & Tunusluoğlu Hüseyin bin Halil & Ziraat \\
\hline 22 & Delihasanoğlu Mehmed bin Osman & Ziraat \\
\hline
\end{tabular}

${ }^{30}$ BOA, ML. VRD. TMT. 4149, kayıtlara göre Elmalı Köyü’nde halkın büyük bölümü gündelikçi ve hizmetkârdır. Bunun yanında kiremitçi ustalar da vardır. 


\begin{tabular}{|c|c|c|}
\hline 23 & Dombicioğlu Mustafa bin Mehmed & Ziraat \\
\hline 24 & Molla Hasanoğlu İbrahim bin Ahmed & Ziraat \\
\hline 25 & Mehmed Efendi bin İbrahim & İmam \\
\hline 26 & Kalafatoğlu Yahya bin Mehmed & Ziraat \\
\hline 27 & Tekeoğlu Halil bin Mustafa & Ziraat \\
\hline 28 & Kendigelenoğlu Hasan bin Ali & Ziraat \\
\hline 29 & Kırıkoğlu Salih bin Abdullah & Ziraat \\
\hline 30 & Fazlıoğlu Ali bin Mustafa & Ziraat \\
\hline 31 & Gökçeoğlu Mehmed bin Musa & Ziraat \\
\hline 32 & Hasancıkoğlu Mustafa bin Ömer & Ziraat \\
\hline 33 & Şabanoğlu Mustafa bin İbrahim & Ziraat \\
\hline 34 & Kel Hasanoğlu Çakar Ali bin Mehmed & Ziraat \\
\hline 35 & Kara Abdullahoğlu Süleyman bin Hasan & Ziraat \\
\hline 36 & Molla Hasanoğlu Çakıl Mehmed bin Ahmed & Ziraat \\
\hline 37 & Hasancıkoğlu Ahmed bin Ömer & Ziraat \\
\hline 38 & Eseoğlu Hüseyin bin Ali & Ziraat \\
\hline 39 & Şabanoğlu Mehmed bin Ömer & Ziraat \\
\hline 40 & Karabaşoğlu Ahmed bin Mehmed Ali & Ziraat \\
\hline 41 & Fazlıŏlu Mehmed bin İsmail & Ziraat \\
\hline 42 & Kırıkoğlu Osman bin Osman & Ziraat \\
\hline 43 & Ömeroğlu İbrahim bin Mehmed Ali & Ziraat \\
\hline 44 & Ramazanoğlu Hüseyin bin mehmed & Ziraat \\
\hline 45 & Kadıoğlu Mustafa bin Ahmed & Ziraat \\
\hline 46 & Gökçeoğlu Osman bin Halil & Ziraat \\
\hline 47 & Taviloğlu Mustafa bin İsmail & Ziraat \\
\hline 48 & Fazlıoğlu Hasan bin Osman & Ziraat \\
\hline 49 & Hocaoğlu Ahmed bin Mustafa & Ziraat \\
\hline 50 & Sahfanoğlu Hasan bin Mehmed & Ziraat \\
\hline 51 & Eseoğlu Osman bin Ali & Ziraat \\
\hline 52 & İsaoğlu Ömer bin Ali & Ziraat \\
\hline 53 & Çobanoğlu İsmail bin Ali & Ziraat \\
\hline 54 & Çobanoğlu Hüseyin bin Ali & Ziraat \\
\hline 55 & Uzun Hasanoğlu İsmail bin Mehmed & Ziraat \\
\hline 56 & Uzun Hasanoğlu Hasan bin Mustafa & Ziraat \\
\hline 57 & Koçoğlu Sarı Ali bin Bekir & Ziraat \\
\hline 58 & İsaoğlu Bekir bin Ali & Ziraat \\
\hline 59 & Şabanoğlu Kısa Osman bin Ahmed & Ziraat \\
\hline 60 & Şabanoğlu Kısa Salih bin Ibrahim & Ziraat \\
\hline 61 & Taviloğlu Mehmed bin Mehmed & Ziraat \\
\hline
\end{tabular}




\begin{tabular}{|c|l|c|}
\hline 62 & Şabanoğlu Kara Mehmed bin Abdülfettah & Ziraat \\
\hline 63 & Pireoğlu Mustafa bin Ahmed & Ziraat \\
\hline 64 & Koçuoğlu Mehmed bin Mustafa & Ziraat \\
\hline 65 & Hatib Said Efendi bin Mustafa & $\begin{array}{c}\text { Hatib ve } \\
\text { Muhtar }\end{array}$ \\
\hline 66 & Hasan Kethüdaoğlu Mustafa bin Mehmed & Ziraat \\
\hline 67 & Merhum Hacı Fettah'ın zevcesi Mısırlı Şerife Molla & Ziraat \\
\hline & Mısırcı Hacı Abdullah & Mısırcı \\
\hline & Menzilcinin Mustafa & Menzilci \\
\hline & Sepetçi Kıptiyân Şaban & Sepetçi \\
\hline
\end{tabular}

Günümüz Adapazarı haritasında Karadere ve Kaymaz aşağıda işaretlenmiştir.

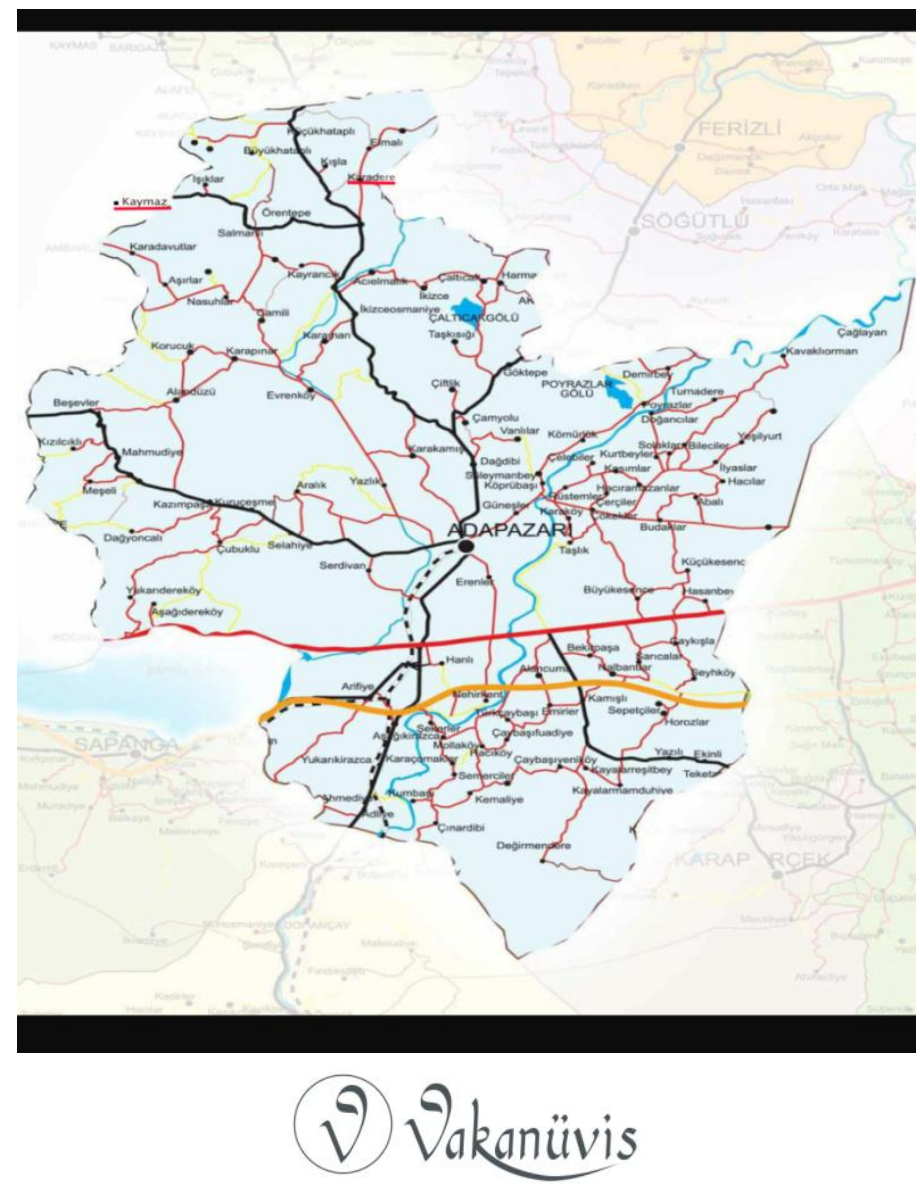




\section{Kaynakça}

\section{Arşiv Belgeleri}

TC Başbakanlık Osmanlı Arşiv Dairesi

Maliye Varidat Temettuat

BOA, ML. VRD. TMT. 1483

BOA, ML. VRD. TMT. 4179

\section{Yazılı Kaynaklar}

Adıyeke, Nuri, "Temettuat Sayımları ve Bu Sayımları Düzenleyen Nizamname Örnekleri", Osmanlı Tarihi Araştırma ve Uygulama Merkezi Dergisi OTAM, c. 11, (2015) s. 769-823.

Barkan, Ömer Lütfi, "Tarihi Demografi Araştırmaları ve Osmanlı Tarihi”, Türkiyat Mecmuası, c. 10, (1953) s. 1-26.

Cengiz, Dilşah, Adapazarı/Söğütlü Karyesi Temettuat Defteri Transkipsiyon ve Değerlendirilmesi, Yayımlanmamış Yüksek Lisans Tezi, Sakarya 2010.

Çetin, Atilla, Kandıra, Kaymas-Akçaova (Akâbâd) Temettuat Defterleri, İzmit 2009.

Çelik, Gülfettin, XVI-XIX. Yüzyıllarda Gebze (Sosyo-Ekonomik Bir Inceleme), Gebze 2003.

Devellioğlu, Ferit, Osmanlıca- Türkçe Ansiklopedik Lügat, Ankara 1962.

Güran, Tevfik, XIX. Yüzyılda Osmanlı Tarımı, İstanbul 1998.

Halaçoğlu, Yusuf, "Klasik Dönemde Osmanlı Devlet Teşkilatı”, Genel Türk Tarihi Ansiklopedisi, c. 6, (2002), s. 171-174.

İnalcık, Halil \& Quataert, Donalt, Osmanlı Imparatorluğu'nun Ekonomik ve Sosyal Tarihi, İstanbul 2004.

İnalcık, Halil, Osmanlı Imparatorluğu Toplum ve Ekonomi, İstanbul 1996.

Kanar, Mehmet, Osmanlı Türkçesi Sözlüğü, İstanbul 2010.

Karpat, Kemal, Osmanlı Nüfusu (1830-1914), İstanbul 2010.

Kaya, Mehmet, "XIX. Yüzyılda İzmit (Kocaeli) Sancağı'nın Demografik Durumu ve İskân Siyaseti", Ankara Üniversitesi, Dil ve Tarih-Coğrafya Fakültesi, Tarih Bölümü, Tarih Araştırmaları Dergisi c.26/41 (2007), s.59-80.

Odabaş, Fatih, XIX. Yüzyılda Adapazarı'nın Sosyo-Ekonomik Yapısı, Yayımlanmamış Yüksek Lisans Tezi, İstanbul 2007.

Pakalın, M. Zeki, "Temettü Vergisi", Osmanlı Tarih Deyimleri ve Terimleri Sözlüğü, c. III, İstanbul 1993.

Sarınay, Yusuf, Başbakanlık Osmanlı Arşivi Rehberi, İstanbul 2010.

Sergün, Ümit, Kocaeli Yarımadası'nda Kırsal Yerleşme, İstanbul 1986.

Subaşı Turgut, "Sultan Abdülmecid Döneminde, Kocaeli", Uluslararası Gazi Akçakoca ve Kocaeli Tarihi Sempozyumu Bildirileri, Kocaeli (2015), s. 647-662.

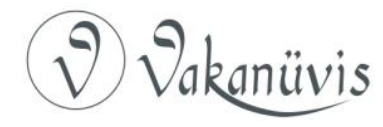


Subaşı, Turgut ve Araz, Mahmut, "Temettuat Defteri Kayıtlarına Göre Söğütlü Karyesi”, Sakarya Üniversitesi Fen Edebiyat Dergisi, 15/1 (2013), s. 122.

Yılmaz, Cevdet, "Türkiye'de Tarihçiler ve Coğrafyacılar Tarafından Farklı Anlamlarda Kullanılan Bir Terim: Divan”, History Studies, c. 2/1 (2010), s. 273309. 